\title{
Effectiveness of Cooperative Learning For Improving Learners' Proficiency Level of English Language in Secondary Level Education in Nepal
}

Keshab Kumar Sijali

\begin{abstract}
This longitudinal research study aims at investigating the effectiveness of cooperative learning $(\mathrm{CL})$ for improving learners' English language proficiency (ELP) level in secondary level education in Nepal. The study comprises 150 learners from grade 10 in the academic session of 2017 among whom 78 learners were chosen for experimental group while 72 for control group. The instruments of proficiency test, questionnaire and interview were used to obtain data that were analyzed using mean, standard deviation, Mann-Whitney Utest and bar graphs. The result shows the effectiveness of CL for improving learners' ELP level that the overall performance of experimental group of students $(M=26.71, S D=$ 4.478) in English language was found far better than that of control group of students ( $M$ $=16.50, \mathrm{SD}=5.619)$ with significant difference $(p<0.001)$.
\end{abstract}

Keywords: Cooperative learning, English language, English language proficiency, Secondary level education, Nepal

\section{Introduction}

Cooperative learning (CL) is an instructional method in which learners in small group work together to complete the assigned task. Jacob (1999) mentions that cooperative learning is an approach of having systematic, structured and diverse types of instructional methods in which small groups of students work together and aid each other in completing academic tasks. In this approach, learners are provided opportunities to enhance social strategies and foster a high degree of autonomy (Jacobs \& McCafferty, 2006). Due to its focus on the completion of task in a structured form of group work, learners can increase retention and improve their problem-solving ability (Millis, 2012). Learners in this approach are found to be intrinsically highly motivated with "high commitment to achieve and high persistence with maximum strategies to deal with anxiety and stress" (Johnson, Johnson, \& Smith, 1995, p. 18). A great strength of CL is that "it provides teachers with many opportunities to instruct children in the social, emotional or moral domains at a time when such instruction is immediately relevant" (Battistich \& Watson, 2003, p. 25). 
There has been much research done on CL (see Ahmadi, Motallebzade, \& Fatemi, 2014; Aicha, 2012; Almuslimi, 2016; Al-Tamimi \& Attamimi, 2014; Chukwuyenum, Nwankwo, \& Toochi, 2014; Keshavarz, Shahrokhi, \& Nejad, 2014; Khan \& Ahmad, 2014; Lin, 2009; Mohammadi \& Davarbina, 2015; Ning, 2010; Siddique \& Singh, 2016; Soraya, 2010). However, no research is found to have been carried out to investigate the effectiveness of CL for the improvement of learners' English language proficiency level in the context of Nepal. Hence, the goal of this study is to fill this gap in the literature.

\section{Theoretical foundation of CL}

John Dewey's brainchild of group activities is considered the foundation of the concept of CLin which learners work together in small groups, cooperating with each other "instead of competing for acknowledgement" (Alharbi, 2008, p. 1). CL is supposedly grounded on the behavioral learning theory, cognitive theory and social interdependence theory (Keshavarz, Shahrokhi, \& Nejad, 2014). Behavioral learning theory assumes that cooperation takes place if learners are reinforced to work in groups to complete the assigned task (Aicha, 2012). Cognitive theory for CL has been rooted with Piaget's theory and Vygotsky's scaffolding theory. Piaget focuses on social interaction in the improvement of student achievement, and Vygotsky's scaffolding theory asserts that learners in group learn best if there is peer support while learning (Lin, 2009). Social interdependence theory contends that learners learn best in cooperation rather than competition (Keshavarz, Shahrokhi, \& Nejad, 2014).

\section{Basic Components of CL}

CL consists of five basic elements, namely positive interdependence, individual and group accountability, face-to-face supportive interaction or opportunity, necessity for interpersonal and small group social skills, and engagement of cooperative groups (Cottell, 2012). Positive interdependence means the equal effort of each of group member to achieve the common goal (Aicha, 2012). In CL, each of the members should have an equal role for the completion of an assigned task. In the same way, the group members are held accountable for contributing to group work, thus ensuring their active involvement in the learning process (Soraya, 2010). Group members also promote each other's success by supporting and encouraging the achievement of a common goal (Al-Tamimi \& Attamimi, 2014). In cooperative learning, learners learn not only the language, but they also learn how to work together to facilitate teamwork with the creation of positive attitudes among the members (Chen \& Wang, 2013). Group processing occurs through reflection on a group session, review of the effectiveness of each group member's role, and redefinition of roles if necessary in order to enhance the groups' collaborative efforts and success completion of its task (Lin, 2009).

\section{Principal Features of $C L$}

One of the major features of CL is that it develops the spirit of positive interdependency among students and discourages the notion of individuality and competition (Agarwal \& Nagar, 2011). It also helps learners improve their "selfesteem, their attitude toward school and their ability to work with others while 
learning with CL" (Farmer, 1999, p. 1). Such collaborative work provides them with opportunities to enhance their social skills through acknowledging another's contribution, asking others to contribute and keeping the conversation calm (Sharma, 2010). CL helps learners enhance their communicative competence through authentic interaction. In other words, it is "effective in terms of providing opportunities for increased meaningful language production, and allows learners to use the language in a natural, supportive and safe environment (Ning, 2010, p. 13).

\section{Types of CL}

Cooperative learning can be classified into three types: informal CL, base group CL and formal CL. Informal CL comprises learners working together "to achieve a joint learning goal in temporary which is especially useful during direct teaching" (Aicha, 2012, p. 12). Base group CL refers to a long-term group with stable membership that aims at "providing constant support and motivation that group members need to achieve educational success instead of working together on a specific learning tasks assignments" (Ning, 2010, p. 25). In, formal groups, which can last from several minutes to several class sessions, learners "work together in order to achieve shared learning goals and complete a specific tasks or assignment" (Aicha, 2012, p. 11).

\section{Cooperative Learning Activities}

One very common CL activity is think/ pair/share (TPS) in which students think about a topic provided by the teacher, pair up with another student to discuss it, and then share their thoughts with the whole class (Grundman, 2002). This technique is found to significantly improve students' achievement (Sumarsih \& Sanjaya, 2013).

Jigsaw is another CL method that can be effectively applied in teaching language. It was first designed by Aronson and his colleagues in the 1970s and later redefined by Slavin. In this activity, learners are divided into heterogeneous home groups and given a a particular aspect of a topic to study and explore; the groups are then reconfigured into new groups so that members from each group share their learning with other groups (Ning, 2010).

A second CL method is group investigation in which learners in their teams determine a general topic and subtopics for investigation, plan for the investigation, carry out the investigation through interaction and interpretation with their teacher, teammates and other teams, and present their findings after which an evaluation session is launched (Aicha, 2012).

Round robin and roundtable are two additional activities. In round robin, each learner in turn shares something with his or her teammates, while in round table, each learner in turn writes one answer on a paper, and then pencil and paper are passed around the group (Kagen, 1993, cited in Grundman, 2002).

\section{The methodology}

The objectives of the present study are to find out the effectiveness of CL for improving learners' English language proficiency in secondary level education in Nepal. 
Hypothesis: The study plans to test the following null hypothesis:

There is no significant difference between the ELP level of cooperatively and traditionally taught learners.

Research question: The study primarily attempts to answer the following question: Is CL effective for the improvement of learners' proficiency level of English language?

Participants: Regarding participants, the study is comprised of 150 learners among whom 78 were randomly chosen for the experimental group with the rest in the control group. The experimental group of learners was taught using the CL approach while the control group of learners was taught in a traditional way for 12 weeks. The cooperative learning activities for the experimental group included TPS, jigsaw, round robin/roundtable and group investigation. Each of the four language skills received the same amount of time. The researcher himself taught both, the experimental and the control groups.

Instruments: With reference to instruments, the study consists of the following three instruments:

1. Proficiency Test: The proficiency test consisting of four papers, namely listening, speaking, reading and writing, was administered to both the experimental and control group of learners after the 12-week period.CL Total score allocated for the test was 40 with equivalent weighting of 10 marks for each of the language skills.

2. Questionnaire: After the practice of CL, the experimental group of students was administered a set of questionnaires with 5 items consisting of the 5-point Likert scale with their specific value ranging from strongly agree $=1$; agree $=2$; undecided $=$
3 ; disagree $=4$ and strongly disagree $=5$ to assess their attitudes regarding the effectiveness of CL to improve their ELP level. The questionnaire was also administered to the control group of students to evaluate their attitudes regarding improvement in their English due to the traditional way of teaching.

3. Interview: With a view to investigating students' views on the effectiveness of the $\mathrm{CL}$ and the traditional approaches, a semistructured interview was conducted on the two groups of students. Seven randomly sampled students from the experimental group and only two students from the control group participated in the interview. The interview, which was optional for ethical reasons, was conducted in English.

\section{Validity and Reliability}

Due attention was given while designing the questionnaire instrument to cover content validity. Further, two researchers from the area of ELT were consulted to establish the face validity of the instrument. The reliability of the questionnaire was assessed using Cronbach's Alpha that comprises the internal consistency of .916, which indicates high reliability. The technique of test-retest was used to establish the reliability of a proficiency test with $\mathrm{r}=.76$, which shows the high correlation. The time interval between these two tests after the practice of CL was 5 days.

\section{Data Analysis}

Mean and standard deviation were used to analyze the data obtained from the proficiency test for comparing the score and Mann-Whitney U-test of non-parametric test in order to find the significant difference between the proficiency level of experimental and control group of learners. 
The data obtained from the questionnaire were analyzed using bar graphs. The researcher used the technique of inductive analysis for analyzing the data obtained from interview. The result obtained from qualitative and quantitative data was mixed adopting the method of concurrent triangulation.

\section{Result}

The result of the study is presented in this section, which provides the detail findings at four different levels of language skill: listening, speaking, reading and writing. Further, it presents the overall proficiency level of learners.

\section{Learners' Listening Level}

The result in Table 1 shows that the experimental group of students $(M=8.63$, $\mathrm{SD}=1.280$ ) performed better than the control group of students $(\mathrm{M}=5.08, \mathrm{SD}=$ 1.912) in listening skill in English with significant difference $(p<0.001)$, which is evidence that CL plays an effective role in improving the listening skill of English learners.

\begin{tabular}{|l|c|c|c|c|c|}
\hline Method of Teaching & N & Mean & SD & $\begin{array}{c}\text { Asymp. Sig. } \\
\text { (2-tailed) }\end{array}$ & Sig \\
\cline { 1 - 4 } Cooperative Learning & 78 & 8.63 & 1.280 & .000 & $\mathrm{p}<0.001$ \\
\cline { 1 - 4 } Traditional Method & 72 & 5.08 & 1.912 & & \\
\hline Total & 150 & 6.93 & 2.397 & & \\
\hline
\end{tabular}

\section{Table 1. Learners' listening level}

In fig. 1, the majority of the experimental group of students have shown their positive attitudes in the role of CL while the majority of the control group of students 
improving the speaking skill of English

\begin{tabular}{|l|l|l|l|c|l|}
\hline Method of Teaching & N & Mean & SD & $\begin{array}{c}\text { Asymp. } \\
\text { Sig. } \\
\text { (2-tailed) }\end{array}$ & Sig \\
\hline Cooperative Learning & 78 & 6.01 & .974 & .000 & $\mathrm{p}<0.001$ \\
\cline { 1 - 4 } Traditional Method & 72 & 4.12 & .978 & & \\
\cline { 1 - 4 } Total & 150 & 5.11 & 1.357 & & \\
\hline
\end{tabular}

learners.

\section{Table 2. Learners' speaking level} In Figure 2, the majority of the experimental group of students have shown their positive attitudes in the role of CL while the majority of the control group of students have shown their negative attitudes in the role of the traditional way of effective in improving learners' reading skill in English.

\begin{tabular}{|l|l|l|l|c|l|}
\hline Method of Teaching & N & Mean & SD & $\begin{array}{c}\text { Asymp. Sig. } \\
\text { (2-tailed) }\end{array}$ & Sig \\
\hline Cooperative Learning & 78 & 6.15 & 1.571 & .000 & $\mathrm{p}<0.001$ \\
\cline { 1 - 4 } Traditional Method & 72 & 4.61 & 1.976 & & \\
\cline { 1 - 4 } Total & 150 & 5.41 & 1.932 & & \\
\hline
\end{tabular}

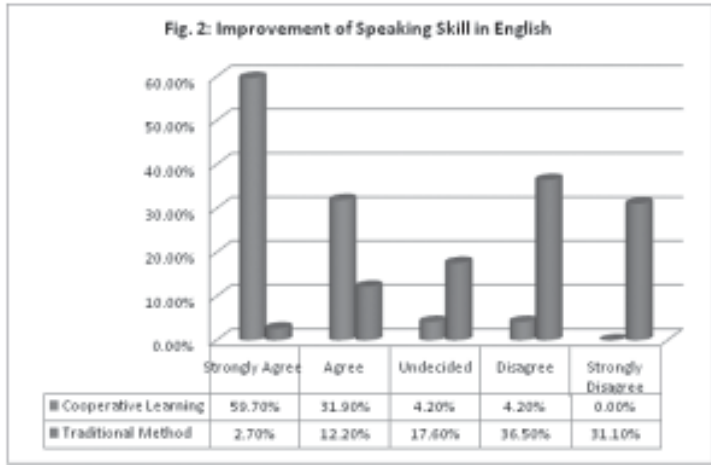

teaching in improving their speaking skill in English.

\section{Learners' Reading Level}

The result in Table 3 also shows that the average score of the experimental group of students $(M=6.15, S D=1.571)$ in reading skill is higher than that of the control group of students $(\mathrm{M}=4.61, \mathrm{SD}=1.976)$ with significant difference $(\mathrm{p}<0.001)$, which is an evidence that cooperative learning is

\section{Table 3. Learners' reading level}

In Figure 3, the majority of experimental group of students have shown their positive attitudes in the role of CL while the majority of the control group of students have shown their negative attitudes in the

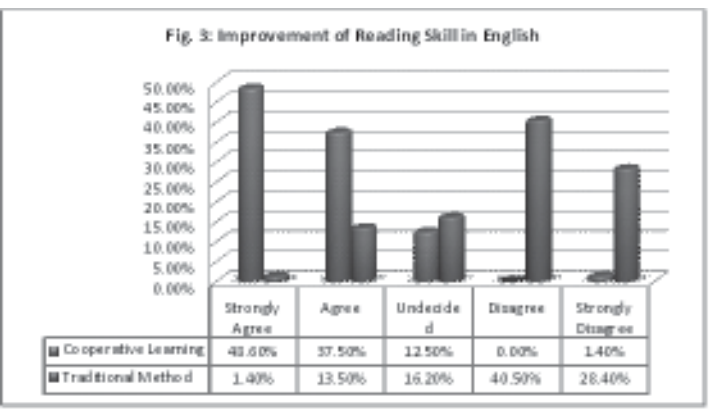


role of traditional way of teaching in improving their reading skill in English.

\section{Learners' Writing Level}

As shown in Table 4, the average score of the experimental group of students $(\mathrm{M}=$ $5.91, \mathrm{SD}=1.949$ ) in writing skill is higher than that of the control group of students $(\mathrm{M}=2.68, \mathrm{SD}=2.318)$ with significant difference $(p<0.001)$, which is evidence that cooperative learning plays a crucial
In Figure 4, the majority of experimental group of students have shown their positive attitudes in the role of CL while the majority of the control group of students have shown their negative attitudes in the role of traditional way of teaching in improving their writing skill in English.

\section{Overall Proficiency Level of Learners}

The result in Table 5 shows that the overall performance of the experimental group of students $(\mathrm{M}=26.71, \mathrm{SD}=4.478)$ in English language is far better than that of the control group of students $(\mathrm{M}=16.50, \mathrm{SD}=5.619)$ with significant difference $(\mathrm{p}<$ $0.001)$, which rejects the null hypothesis mentioned in the section 3.2.1; it can therefore

role in improving learners' writing skill in

English.

\section{Table 4. Learners' writing level}

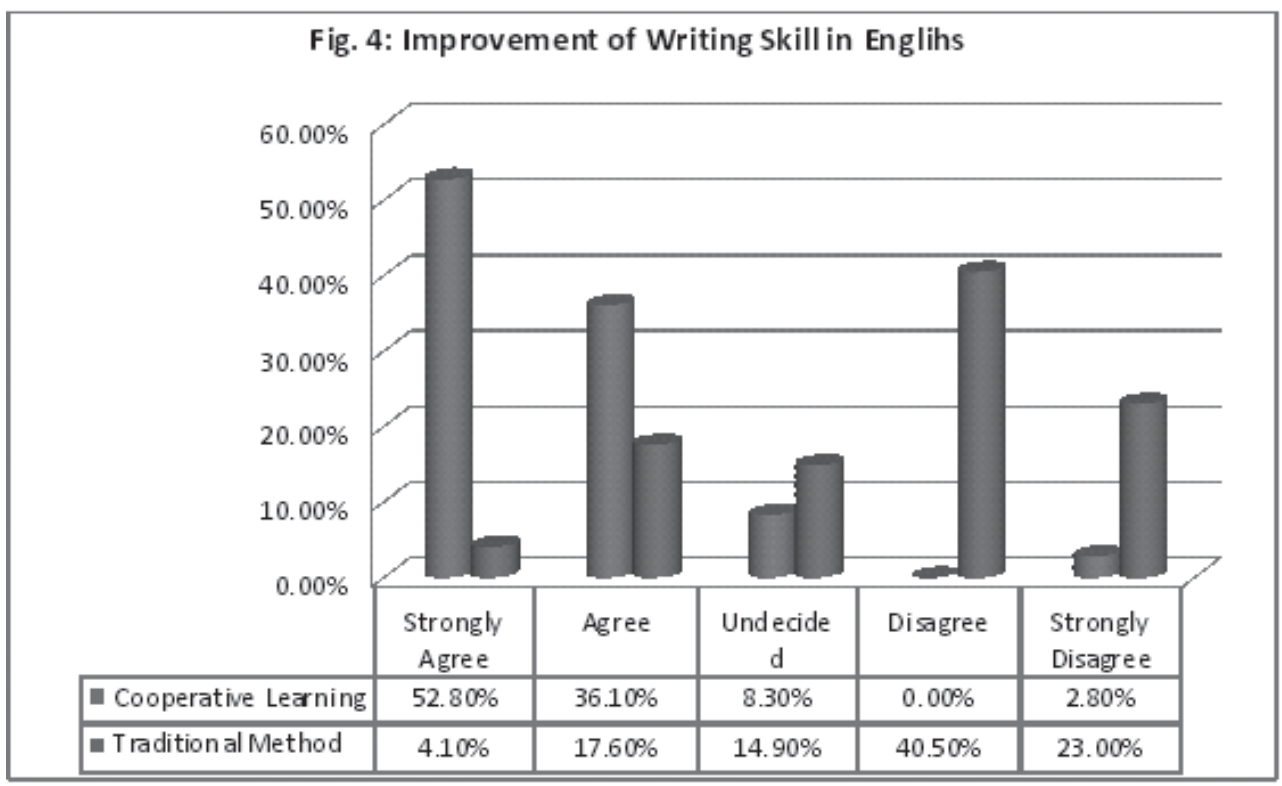


concluded that CL plays an effective role in improving learners' proficiency level of

\begin{tabular}{|l|c|l|l|c|l|}
\hline Method of Teaching & N & Mean & SD & $\begin{array}{c}\text { Asymp. Sig. } \\
\text { (2-tailed) }\end{array}$ & Sig \\
\hline Cooperative Learning & 78 & 5.91 & 1.949 & .000 & $\mathrm{p}<0.001$ \\
\cline { 1 - 5 } Traditional Method & 72 & 2.68 & 2.318 & & \\
\cline { 1 - 5 } Total & 150 & 4.36 & 2.673 & & \\
\hline
\end{tabular}

English language.

\section{Table 5. Learners' overall proficiency level of English}

In Figure 5, the majority of the experimental group of students have shown their positive attitudes in the role of CL while the majority of the control group of

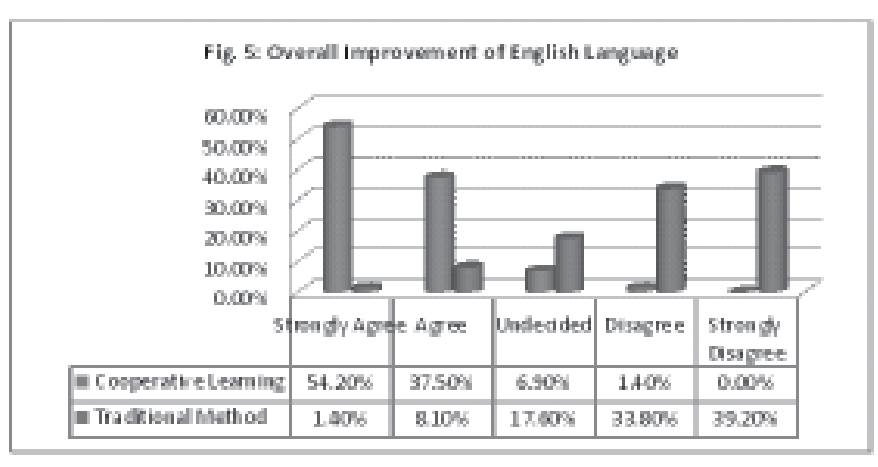

been improved due to support of my friends while working in group. I think cooperative language learning is the best way of improving English language. [EGS1]

The following excerpt of a participant is also consistent with the above-mentioned view as:

Cooperative learning is helpful in improving my English language. In previous year, I didn't have good capabilities to read, write and speak in English. After the practice of cooperative learning, my speaking, reading, writing and listening has been improved a lot. I prefer cooperative learning. [EGS2] students have shown their negative attitudes in the role of traditional way of teaching for the overall improvement of their ELP level.

This result is also supported by the view of experimental group of students (EGS) that they have expressed their positive attitudes in the role of CL in the improvement of their ELP. Some of the excerpts can be extracted as:

Cooperative language learning has a vital role in improving my English language. My English language has
Another participant points out the role of CL not only for the improvement of ELP level, but also for the enhancement of social skills as:

Cooperative learning has played an important role for the improvement of my English language. With the support of interaction with group members during class activities; it has increased my level in different skills of English language. It has also helped to maintain good relation among group members which has highly helped for the improvement of English language. [EGS3]

Along with the improvement of English language, CL was also found to be interesting, effective and supportive in working in teams as:

I like the way of learning through cooperative learning. It has a vital role 
in improving my English language. My speaking skill in English has been improved a lot due to cooperative learning as compared to old days. Not only this, but it has helped me to improve listening skill, reading skill and writing skill. It is also helping me to bring team work and mutual understanding with my friends. It is enjoyable, useful and advantageous too. [EGS4]

The following excerption also advocates in favor of CL for improving ELP level and raises a voice against the traditional way of teaching as:

Cooperative learning has helped me in improving my overall reading, writing, speaking as well as listening in English. The traditional way of teaching was boring and ineffective. I think teaching must be interesting, effective and useful. I have found cooperative learning as very practicable, effective and interesting. [EGS5]

The following view of another participant is also consistent with the aforementioned view regarding the role of CL and adds its effectiveness in problem-solving while learning team work as:

Cooperative learning has a great role in improving my English language as it has given me opportunities to share knowledge with others in English. In my view, this way of learning is effective as I don't feel bored while studying in the class. Studying and working with friends makes my mind refreshed and able to solve the problem using each other's support. [EGS6]
Beside the significance of CL in improving ELP, the learners also find it supportive in handling the challenges and obstacles encountered while learning as:

In my view, cooperative language learning has helped me to improve all my language skills like listening, speaking, reading and writing. Many challenges and obstacles are seen while learning. Through cooperative learning, I become capable of handling them easily while working with the members in group. [EGS7]

In the same way, the control group of students (CGS) was also interviewed to gather information regarding the improvement of their ELP. In contrast to the views of EGS, CGS expressed their negative perception in the role of the traditional way of teaching. They expressed their views that the traditional way of teaching is not sufficient enough to enhance ELP. They have experienced the need for other methods of teaching rather than traditional ways. For instance, an excerpt of a student in the CGS can be extracted as:

In my view, the traditional way of teaching is not sufficient for improving my English because it doesn't provide the opportunity to take part in the activities. I think, modern techniques should be used in the class. [CGS1]

The view of another student belonging to CGS is also consistent with the abovementioned view as:

I don't get chance to practice in English language. I have to just listen only the lecture of teacher in the class. I feel traditional way of teaching doesn't support to improve my English language. [CGS2] 
In such context, with reference to the views of EGS, CL seems to be effective for the enhancement of their ELP level.

\section{Discussions and Implications}

After the analysis of both qualitative and quantitative data, the result shows that CL is effective in improving learners' ELP level. This result is consistent with the previous research (see Ahmadi, Motallebzade, \& Fatemi, 2014; Aicha, 2012; Almuslimi, 2016; Al-Tamimi \& Attamimi, 2014; Chukwuyenum, Nwankwo, \& Toochi, 2014; Keshavarz, Shahrokhi, \& Nejad, 2014; Khan \& Ahmad, 2014; Lin, 2009; Mohammadi \& Davarbina, 2015; Ning, 2010; Siddique \& Singh, 2016; Soraya, 2010). But, the peer-mediated model of learning is criticized to be a "failure to address the needs of the more able pupil who may require more independent learning and flexibility" (Jolliffe, 2007, p. 14). However, it is suggested that ELT practitioners implement CL since it develops the "spirit of positive interdependency among students and discourages the notion of individuality and competition creating a positive classroom climate" (Ghaith \& Kawtharani, 2006). There are, however, a number of factors to take into consideration while applying this approach, such as classroom management, clear definition of the specific tasks, group assignments, instruction on group processing, and monitoring and assessment (Farmer, 1999). One more aspect to be paid due attention in the application of CL is grouping students. While grouping learners for CL, Murdoch \& Wilson (2007) suggest different ways such as teacher- and student-selected groups, and long-term 'base' groups. The important point is that students are placed in "an all-win atmosphere" (Farmer, 1999, p. 1).

\section{Conclusion}

This 12-week longitudinal study, based on a mixed-method approach following the paradigm of pragmatism, aimed to find out the effectiveness of CL for improving learners' proficiency level of English language in secondary level education in Nepal and successfully investigated the determined objective. The findings of the study indicate that CL is more effective than the traditional way of teaching as a means to improve ELP.

\section{Limitations of the Study}

This study is not beyond its limitations since it consists of a small sample size. Second, the results could reflect the genuine improvement in the proficiency level of experimental group of learners if a pre-test was conducted before the practice of CL. In such context, their previous linguistic background might have also influenced the result. Third, the instrument of the proficiency test includes a writing part for which multiple marking techniques were implemented in order to increase the reliability in the writing score. However, there might be the subjective influence of the checker while assessing it.

\section{Suggestions for Future Research}

While measuring the effectiveness of CL for improving learners' ELP, the study has been confined only to the view of learners. The research could be enriched if the voice of English teachers' regarding the effectiveness of $\mathrm{CL}$ were given a position in the study. Hence, future research could be carried out including the view of English teachers. In addition, the present study 
examined the effectiveness of CL in secondary-level education; future research could also investigate the effectiveness of $\mathrm{CL}$ in another level.

\section{Acknowledgements}

The present study has been possible only with the kind support, long patience and cooperation of research participants. Hence, the grade 10 students in the academic session of 2017 belonging to Gauri Shankar Higher Secondary School, Nigharh-8, Bara deserve special thanks for their active participation in the study.

\section{References}

Agarwal, R., \& Nagar, N. (2011). Cooperative Learning. India: Kalpaz Publications.

Ahmadi, N., Motallebzade, K., \& Fatemi, M. A. (2014). The Effect of Cooperative Learning Strategies on Iranian Intermediate Students' Writing Achievement. Open Access Library Journal , 1, 1-9.

Aicha, A. (2012). Cooperative Learning Strategies in Enhancing Students' Writing Proficiency. MA Thesis, The University of Mohamed KhidherBiskra.

Alharbi, L. A. (2008). The Effectiveness of Using Cooperative Learning Method on ESL Reading Comprehension Performance Students' Attitudes Toward CL and Students Motivation Toward Reading of Secondary Stage in Saudi Public Girls' Schools. PhD Thesis, West Verginia University, West Verginia.
Almuslimi, F. K. (2016). The Effect of Cooperative Learning Strategy on English Reading Skills of 9th Grade Yemeni Students and their Attitudes towards the Strategy. International Journal of Research in Humanities, Arts and Literature , 4 (2), 41-58.

Al-Tamimi, N. O., \& Attamimi, R. A. (2014). Effectiveness of Cooperative Learning in Enhancing Speaking Skills adn Attitudes towards Learning English. International Journal of Linguistics , 6 (4), 27-45.

Battistich, V., \& Watson, M. (2003). Fostering Social Development in PreSchool and the Early Elementary Grades through Cooperative Classroom Activities. In R. Gillies, \& A. Ashman (Eds.), Cooperative Learning: The Social and Intellectual Outcomes of Learning in Groups (pp. 1935). NY: Routledge Falmer.

Chen, J., \& Wang, Y. (2013). A Study of Cooperative Learning in Higher College English Teaching. Theory and Practice in Language Studies , 3 (7), 12581263.

Chukwuyenum, A. N., Nwankwo, A. E., \& Toochi, U. (2014). Impact of Cooperative Learning on English Language Achievement among Senior Secondary School Students in Delta State, Nigeria: Implication for Counseling. Journal of Emerging Trends in Educational Research and Policy Studies , 5 (7), 70-76.

Cottell, P. G. (2012). Cooperative Learning in Accounting. In B. J. Millis (Ed.), Cooperative Learning in Higher 
Education (pp. 11-34). Stylus Publishing.

Farmer, L. S. (1999). Cooperative Learning Activities in the Library Media Centre. US: Teacher Ideas Press.

Ghaith, G., \& Kawtharani, A. (2006). Using Cooperative \& SL Learning with Primary School Students. In J. C. Richards (Ed.), Cooperative Learning $\mathcal{E}$ $S L$ Teaching. Cambridge Language Education.

Grundman, J. (2002). Cooperative Learning in an English as a Second Language Classroom. MA Thesis, Hamline University.

Jacob, E. (1999). Cooperative Learning in Context: An Educational Innovation in Everyday Classroom. Albany: State University of New York Press.

Jacobs, G. M., \& McCafferty, S. G. (2006). Connection Between Cooperative \& SL Learning. In J. C. Richards (Ed.), Cooperative Learning \& SL Teaching. Cambridge Language Education.

Johnson, D. W., Johnson, R. T., \& Smith, K. A. (1995). Cooperative Learning and Individual Student Achievement. In J. Pedersen, \& A. D. Digby (Eds.), Secondary Schools and Cooperative Learning : Theories, Models and Strategies (pp. 3-54).

Jolliffe, W. (2007). Cooperative Learning in The Classroom: Putting it into Practice. London: A SAGE Publication.

Keshavarz, S. M., Shahrokhi, M., \& Nejad, M. R. (2014). The Effect of Cooperative Learning Teachnique on Promoting
Writing Skill of Iranian EFL Learners. International Journal of Language Learning and Applied Linguistics World , 5 (1), 78-90.

Khan, S. A., \& Ahmad, R. N. (2014). Evaluation of the Effectiveness of Cooperative Learning Metod Versus Traditional Learning Method on the Reading Comprehension of the Students. Journal of Research and Reflections in Education , 8 (1), 55-64.

Lin, M. (2009). Effects of Cooperative Learning on the Oral Proficiency of Chinese Students in the Tertiary Level EFL Classroom. PhD Thesis, The University of Leicester.

Millis, B. J. (2012). Why Faculty Should Adopt Cooperative Learning Approaches. In B. J. Millis (Ed.), Cooperative Learning in Higher Education (pp. 1-10). Stylus Publishing.

Mohammadi, A., \& Davarbina, M. (2015). The Effect of Cooperative Learning Techniques on Reading Comprehension Ability of Iranian EFL Learners. International Journal of Social Science and Education , 5 (3), 525-531.

Murdoch, K., \& Wilson, J. (2007). Cooperative Learning : Little Books of Big Ideas. Curriculum Cooperation.

Ning, H. (2010). An Investigation of the Use of Cooperative Learning in Teaching English as a Foreign Language with Tertiary Education Learners in China. PhD Thesis, The University of Canterbury. 
Sharma, U. N. (2010). A Course in ELT Methods. Kathmandu: Highland Publication Pvt. Ltd.

Siddique, M., \& Singh, M. K. (2016). Effectiveness of Cooperative Learning in Enhancing Students' Essary Writing Skills in Pakistani Colleges. International Journal of Humanities and Social Science Invention , 5 (8), 68-70.

Soraya, B. (2010). Enhancing Students' Oral Proficiency through Cooperative Group Work. MA Thesis, Constantine University.

Sumarsih, M. P., \& Sanjaya, D. (2013). TPS as an Effective Technique to Enhance the Students' Achievement on Writing Descriptive Text. elt , 6 (12), 106-113.

\section{Contributor}

Keshab Kumar Sijali is currently a PhD scholar in ELT and the head of the Department of ELT, Shree Gauri Shankar Higher Secondary School, Nijgarh-8, Вara. He is a life member of NELTA and Joint Secretary of its Bara Branch. He has taught English at graduate and undergraduate levels for a decade, and published more than half a dozen research articles on ELT issues in different international peerreviewed journals. His research interests include ELT issues and ICT in teaching English. 